\title{
Palmoplantar keratoderma-deafness syndrome
}

INSERM

\section{Source}

INSERM. (1999). Orphanet: an online rare disease and orphan drug data base.

Palmoplantar keratoderma-deafness syndrome. ORPHA:2202

Palmoplantar keratoderma-deafness syndrome is a keratinization disorder characterized by focal or diffuse palmoplantar keratoderma. A patchy distribution is observed with accentuation on the thenars, hypothenars and the arches of the feet. The disease becomes apparent in infancy and is associated with sensorineural hearing loss that shows a variable age of onset. Due to genetic and clinical similarities, it has been proposed that palmoplantar keratoderma-deafness syndrome, knuckle padsleukonychia-sensorineural deafness-palmoplantar hyperkeratosis syndrome and keratoderma hereditarium mutilans may represent variants of one broad disorder of syndromic deafness with heterogeneous phenotype. The disease is transmitted in an autosomal dominant manner with incomplete penetrance. 